\title{
Low calcium:phosphorus ratio in habitual diets affects serum parathyroid hormone concentration and calcium metabolism in healthy women with adequate calcium intake
}

\author{
Virpi E. Kemi ${ }^{1}$, Merja U. M. Kärkkäinen ${ }^{1}$, Hannu J. Rita ${ }^{2}$, Marika M. L. Laaksonen ${ }^{1}$, Terhi A. Outila ${ }^{1}$ and \\ Christel J. E. Lamberg-Allardt ${ }^{1 *}$ \\ ${ }^{1}$ Calcium Research Unit, Department of Applied Chemistry and Microbiology, PO Box 66, FI-00014 University of Helsinki, \\ Helsinki, Finland \\ ${ }^{2}$ Department of Forest Resource Management (Statistics and Methodology), University of Helsinki, Helsinki, Finland
}

(Received 30 March 2009 - Revised 27 August 2009 - Accepted 28 August 2009 - First published online 28 September 2009)

\begin{abstract}
Excessive dietary $\mathrm{P}$ intake alone can be deleterious to bone through increased parathyroid hormone (PTH) secretion, but adverse effects on bone increase when dietary $\mathrm{Ca}$ intake is low. In many countries, $\mathrm{P}$ intake is abundant, whereas Ca intake fails to meet recommendations; an optimal dietary $\mathrm{Ca}: \mathrm{P}$ ratio is therefore difficult to achieve. Our objective was to investigate how habitual dietary Ca:P ratio affects serum PTH (S-PTH) concentration and other $\mathrm{Ca}$ metabolism markers in a population with generally adequate $\mathrm{Ca}$ intake. In this cross-sectional analysis of 147 healthy women aged 31-43 years, fasting blood samples and three separate 24-h urinary samples were collected. Participants kept a 4-d food record and were divided into quartiles according to their dietary Ca:P ratios. The 1 st quartile with $\mathrm{Ca}: \mathrm{P}$ molar ratio $\leq 0 \cdot 50$ differed significantly from the 2 nd (Ca:P molar ratio 0.51-0.57), 3rd (Ca:P molar ratio 0.58-0.64) and 4th (Ca:P molar ratio $\geq 0.65)$ quartiles by interfering with Ca metabolism In the 1st quartile, mean S-PTH concentration $(P=0 \cdot 021)$ and mean urinary $\mathrm{Ca}(\mathrm{U}-\mathrm{Ca})$ excretion were higher $(P=0 \cdot 051)$ than in all other quartiles. These findings suggest that in habitual diets low Ca:P ratios may interfere with homoeostasis of $\mathrm{Ca}$ metabolism and increase bone resorption, as indicated by higher S-PTH and U-Ca levels. Because low habitual dietary Ca:P ratios are common in Western diets, more attention should be focused on decreasing excessively high dietary $\mathrm{P}$ intake and increasing $\mathrm{Ca}$ intake to the recommended level.
\end{abstract}

Ca:P ratio: Parathyroid hormone: Ca metabolism: $P$ intake: $C a$ intake

Osteoporosis is a major public health problem and a costly disease worldwide. From a nutritional point of view, the importance of adequate vitamin $\mathrm{D}$ and $\mathrm{Ca}$ intake for bone health is well established ${ }^{(1-3)}$. Nevertheless, less consensus exists about whether the intake of $\mathrm{Ca}$ and $\mathrm{P}$, the main boneforming minerals, must exist in a certain ratio in adult diets to ensure optimal bone health. Based on calculations of recommended dietary $\mathrm{Ca}$ and $\mathrm{P}$ intakes, the optimal dietary $\mathrm{Ca}: \mathrm{P}$ molar ratio is suggested to be $1^{(4-7)}$, corresponding to a $\mathrm{Ca}: \mathrm{P}$ weight ratio of $1 \cdot 3$. However, in many countries, dietary $\mathrm{P}$ intake is two- to threefold higher than recommended levels ${ }^{(8-11)}$, while total dietary $\mathrm{Ca}$ intake remains below nutritional recommendations ${ }^{(11-16)}$. These dietary habits lead to the lower dietary $\mathrm{Ca}: \mathrm{P}$ ratios observed in various countries in recent years ${ }^{(8,11,17-19)}$.

The hypothesis of adverse effects of diets with a low Ca:P ratio originated from animal model studies, where animals fed a low Ca:P ratio diet manifested secondary hyperparathyroidism, loss of bone and osteopenia ${ }^{(6)}$. In addition, a high $\mathrm{Ca}: \mathrm{P}$ ratio due to low $\mathrm{P}$ intake was found to be favourable for bone mineralisation in adult rats, as it increased $\mathrm{Ca}$ absorption $^{(20)}$. Relative to the number and quality of animal studies, the effects of dietary $\mathrm{Ca}: \mathrm{P}$ ratios on $\mathrm{Ca}$ and bone metabolism in human subjects have been investigated little. Furthermore, whether the dietary $\mathrm{Ca}: \mathrm{P}$ ratio is clinically significant in adult human subjects has been debated ${ }^{(21,22)}$. Some earlier findings in young females have supported the importance of a sufficient dietary $\mathrm{Ca}: \mathrm{P}$ ratio in bone health in epidemiological ${ }^{(23,24)}$, intervention ${ }^{(25)}$ or short-term controlled studies ${ }^{(26,27)}$.

Parathyroid hormone (PTH) is a major regulator of $\mathrm{Ca}, \mathrm{P}$ and bone metabolism. $\mathrm{Ca}$ and $\mathrm{P}$ have opposite effects on serum PTH (S-PTH) concentration, as dietary $\mathrm{P}$ has been found to increase S-PTH concentrations ${ }^{(25,26)}$ by decreasing serumionised $\mathrm{Ca}(\mathrm{S}-\mathrm{iCa})$ concentration $^{(28)}$ and by directly affecting PTH secretion ${ }^{(29)}$, probably through the Na-phosphate cotransporter in the parathyroid gland ${ }^{(30)}$, while $\mathrm{Ca}$ administration has been demonstrated to decrease S-PTH ${ }^{(31,32)}$ through

Abbreviations: ANCOVA, analysis of covariance; LSD, least significant difference method; PTH, parathyroid hormone; S-Ca, serum Ca; S-iCa, serum-ionised Ca;

S-Pi, serum phosphate; S-PTH, serum PTH; S-25(OH)D, serum 25-hydroxy vitamin D; U-Ca, urinary Ca; U-Pi, urinary phosphate.

* Corresponding author: Christel J. E. Lamberg-Allardt, fax +358 9 19158269, email christel.lamberg-allardt@helsinki.fi 
an increase in $\mathrm{S}-\mathrm{iCa}^{(28)}$. Intermittent administration of PTH stimulates bone formation ${ }^{(33)}$ and increases trabecular bone mass ${ }^{(34)}$, while continuous excessive PTH secretion increases bone turnover ${ }^{(35,36)}$ and releases $\mathrm{Ca}$ and $\mathrm{P}$ from bone.

$\mathrm{Ca}$ and $\mathrm{P}$ metabolism is tightly bound together, which is reflected in, for instance, the S-PTH-mediated regulation of urinary $\mathrm{Ca}(\mathrm{U}-\mathrm{Ca})$ and urinary phosphate (U-Pi) excretions. In normal physiological conditions, an increase in S-PTH concentration results in lower U-Ca and higher U-Pi excretion. Understandably, as both dietary $\mathrm{Ca}$ and $\mathrm{P}$ intakes affect $\mathrm{S}-\mathrm{PTH}$, an increase in dietary $\mathrm{Ca}$ intake elevates U-Ca excretion $^{(27,37)}$, while high $\mathrm{P}$ intake per $s e^{(5,38)}$ or together with low $\mathrm{Ca}$ intake ${ }^{(26,27)}$ decreases U-Ca excretion. Decreased S-PTH concentration, in turn, leads to higher U-Ca and lower U-Pi excretion. U-Pi excretion diminishes, as decreased S-PTH inhibits the activity of Na-phosphate co-transporters in kidneys ${ }^{(39)}$.

Our objective here was to examine how habitual dietary $\mathrm{Ca}: \mathrm{P}$ ratio affects S-PTH concentration and other $\mathrm{Ca}$ metabolism markers in healthy premenopausal women. We hypothesised that low dietary $\mathrm{Ca}: \mathrm{P}$ ratios have a more deleterious impact than high $\mathrm{Ca}: \mathrm{P}$ ratios on $\mathrm{Ca}$ metabolism. Since dietary $\mathrm{Ca}$ intake in Scandinavian countries generally meets nutritional recommendations, we were able to determine whether the optimal dietary $\mathrm{Ca}: \mathrm{P}$ molar ratio of 1 is achieved among participants whose habitual dietary $\mathrm{Ca}$ intake is at the recommended level $(\geq 800 \mathrm{mg} / \mathrm{d})^{(4)}$.

\section{Participants and methods}

\section{Participants}

Our participants represent a subgroup of randomly selected 31- to 43-year-old Finnish women. Details about these cross-sectional study participants have been provided elsewhere ${ }^{(40)}$. Only women with no illnesses or medications affecting $\mathrm{Ca}$ metabolism were included. Women with no or irregular menstruation as well as those with incomplete 4-d food records were excluded. Our final study group comprised 147 healthy premenopausal women, whose oestrogen status was presumed to be reasonable normal due to regular menstruation. Before the study, each participant gave her informed consent to the procedures, which were conducted in accordance with the Helsinki Declaration. The Helsinki University Ethics Committee approved the study protocol.

\section{Questionnaire and dietary assessment}

A questionnaire was used to collect information on weight, height, smoking habits and alcohol consumption of participants. In addition, the questionnaire requested information on age, age at menarche, past medical history (e.g. contraceptives used) and menstruation cycle.

To gather data on habitual energy and nutrient intakes, participants were instructed on how to keep a 4-d food record, which included three weekdays and $1 \mathrm{~d}$ of the weekend. Participants were advised to maintain their habitual food intakes during this period and to record all foods and beverages immediately after consumption. A nutritionist together with the participant checked the 4-d food record. We calculated participants' habitual dietary intakes with a computer-based program, the Unilever Dietary Analysis Program (Becel Palvelu Paasivaara Oy, Finland, 1989), based on the food composition database (Fineli) of the Finnish National Public Health Institute.

\section{Study design}

Participants' dietary $\mathrm{Ca}: \mathrm{P}$ ratios were calculated based on the information of $\mathrm{Ca}(\mathrm{mg} / \mathrm{d})$ and $\mathrm{P}(\mathrm{mg} / \mathrm{d})$ intakes provided in the 4-d food record. Weight $\mathrm{Ca}: \mathrm{P}$ ratios were converted into molar ratios by using molecular weight of $\mathrm{Ca}(40.08 \mathrm{~g} / \mathrm{mol})$ and $\mathrm{P}$ $(30.97 \mathrm{~g} / \mathrm{mol})$. Both molar and weight ratios of each $\mathrm{Ca}: \mathrm{P}$ quartile are presented in Table 1. To examine the effects of different dietary $\mathrm{Ca}: \mathrm{P}$ ratios on $\mathrm{S}-\mathrm{PTH}$ and $\mathrm{Ca}$ metabolism markers, we divided participants into quartiles according to their dietary $\mathrm{Ca}: \mathrm{P}$ molar ratios. Characteristics of quartiles are presented in Table 1 . In addition, since we found that the 1st quartile differed from all other quartiles in effects on S-PTH and several other Ca metabolism markers and the 2nd, 3rd, and 4th quartiles had similar effects, we also compared the 1st quartile to the combined group of the other quartiles.

\section{Sampling and biochemical measurements}

On the study days, blood samples were taken anaerobically between 07.30 hours and 09.15 hours after a 12 -h overnight fast. In addition, 24-h urine was collected three times during the study. The urine and separated serum samples were stored at $-20^{\circ} \mathrm{C}$ until analysed. The S-iCa concentration was analysed with an ion-selective analyser (Microlyte 6, Thermo Electron Corporation, Vantaa, Finland). The intra-assay $\mathrm{CV}$ was $1.6 \%$ for S-iCa. The serum-intact PTH concentration was measured using an immunoradiometric assay (Nichols Institute, Juan San Capistrano, CA, USA), with $10-65 \mathrm{ng} / \mathrm{l}$ as the reference range. Intra- and interassay $\mathrm{CV}$ for serum-intact PTH were 3.7 and $1 \%$, respectively. The serum 25-hydroxy vitamin D $(\mathrm{S}-25(\mathrm{OH}) \mathrm{D})$ concentration was measured by a RIA (Dia Sorin, Inc., Stillwater, MN, USA). The intra- and interassay CV were 10.1 and $14.9 \%$, respectively. Serum $\mathrm{Ca}(\mathrm{S}-\mathrm{Ca})$ and phosphate $(\mathrm{S}-\mathrm{Pi})$, and $\mathrm{U}-\mathrm{Ca}$ and phosphate (U-Pi) concentrations were measured by routine laboratory methods using an Elan Automatic Analyser (Eppendorf-Netheler-Hinz GmbH, Hamburg, Germany). CV \% for S-Ca and U-Ca was $1.20-1.60 \%$, and for S-Pi and U-Pi it was $2.90 \%$. To calculate U-Ca and $\mathrm{U}-\mathrm{Pi}$ values, the averages of three separate urine collections, corrected with urinary creatinine excretion, were used.

\section{Statistical analysis}

Statistical approaches. Power calculation based on S-PTH concentration (expected difference between quartiles in mean S-PTH concentration $12 \mathrm{ng} / \mathrm{l}$ ), assuming $90 \%$ power with $\alpha=0.05$, indicated that a sample size of eleven in each group was adequate ${ }^{(41)}$. Subject characteristics between quartiles were compared by ANOVA. The differences in the averages of the dependent variables between the $\mathrm{Ca}: \mathrm{P}$ quartiles were compared with ANOVA and analysis of covariance (ANCOVA). ANCOVA was used because it enables inclusion of both categorical (e.g. use of contraceptives) and continuous 
(e.g. S-iCa) explanatory variables. Furthermore, ANCOVA was used to exclude the possibility that differences found with ANOVA are not due to differences in relevant covariates. For pairwise comparison when ANOVA or ANCOVA $P$-values were below 0.05, Fisher's least significant difference method (Fisher's LSD) was used. We used an SPSS software program (version 15.0, SPSS, Inc., Chicago, IL, USA, 2006) in a Windows environment for all statistical analyses. Results were considered statistically significant at $P<0 \cdot 05$. Data are presented as means and standard error of means.

Covariates. Several factors are known to affect S-PTH concentration. Among these are serum variables $(\mathrm{S}-25(\mathrm{OH}) \mathrm{D}$ and $\mathrm{S}-\mathrm{iCa})$ and the use of contraceptives ${ }^{(42)}$. When the means of S-iCa, S-Ca and S-Pi were compared, S-PTH was included in covariates (Table 2). In addition, S-Pi was included in covariates when comparing the means of $\mathrm{S}-\mathrm{iCa}$ and S-Ca (Table 2). Na intake is known to affect U-Ca and U-Pi excretion; therefore, when the means of U-Pi and U-Ca were compared, $\mathrm{Na}$ intake was included in covariates. We excluded age from the covariates, as all participants represented the same age group and all were premenopausal females. Energy intake was also excluded because $\mathrm{Ca}$ and $P$ intakes correlated well with energy intake. Since body weight and BMI had no effects on the variables measured, they were excluded from the covariates. In summary, we chose covariates that correlated with the outcome parameter or covariates known to affect outcome according to the literature.

\section{Results}

\section{Baseline characteristics}

The baseline characteristics of the 147 participants are displayed in Table 1.

Habitual dietary calcium and phosphorus intake. Participants' average dietary intake of $\mathrm{Ca}$ and $\mathrm{P}$, and $\mathrm{P}$ intake from milk and cheese are presented in Table 1 . Forty-four participants had a dietary $\mathrm{Ca}$ intake below recommended levels ${ }^{(4,43)}$; their mean intake was $647 \mathrm{mg} / \mathrm{d}$ (SEM 21.6). In the Ca:P quartiles, the number of participants with a dietary $\mathrm{Ca}$ intake below recommendations varied, being the highest in the 1st quartile ( $n$ 26, $n 13, n 0$ and $n 5$ in the 1st, 2nd, 3rd and 4th quartiles, respectively; Table 1). Among all study participants, the lowest individual dietary Ca intake was $200 \mathrm{mg} / \mathrm{d}$ and the highest was $2739 \mathrm{mg} / \mathrm{d}$, while the lowest individual P intake corresponded exactly to nutritional recommendations for $\mathrm{P}^{(4,43)}$ and the highest $(3010 \mathrm{mg} / \mathrm{d})$ exceeded the recommendations fivefold ${ }^{(43)}$. The 5th, 50th and 95th percentiles of $\mathrm{Ca}$ and $\mathrm{P}$ intake in each $\mathrm{Ca}: \mathrm{P}$ quartile are presented in Fig. 1.

Habitual dietary calcium:phosphorus ratio. In line with the National FINDIET 2007 Survey results ${ }^{(8)}$, the average habitual dietary Ca:P ratio of our participants (Table 1) corresponded to the ratio in Finnish females. The molar ratio of dietary $\mathrm{Ca}: \mathrm{P}$ varied between 0.22 and 0.91 , corresponding to a Ca:P weight ratio of $0 \cdot 29-1 \cdot 18$; thus, none of the participants achieved the suggested dietary $\mathrm{Ca}: \mathrm{P}$ molar ratio of $1^{(4-7)}$. The mean molar $\mathrm{Ca}: \mathrm{P}$ ratios of study participants in each quartile of dietary $\mathrm{Ca}$ and $\mathrm{P}$ intakes are presented in Fig. 2. Among all participants, the Ca:P molar ratio at the 
Table 2. Mean values of serum-ionised calcium (S-iCa), calcium (S-Ca) and phosphate (S-Pi) concentrations (Mean values with their standard errors)

\begin{tabular}{|c|c|c|c|c|c|c|c|}
\hline \multirow[b]{2}{*}{ Quartiles and mean } & \multicolumn{2}{|c|}{ S-iCa $(\mathrm{mmol} / \mathrm{l})$} & \multicolumn{2}{|c|}{$\mathrm{S}-\mathrm{Ca}(\mathrm{mmol} / \mathrm{l})$} & \multicolumn{2}{|c|}{$\mathrm{S}-\mathrm{Pi}(\mathrm{mmol} / \mathrm{l})$} & \multirow[b]{2}{*}{ Number of participants } \\
\hline & Mean & SEM & Mean & SEM & Mean & SEM & \\
\hline 1st Quartile & $1 \cdot 204^{*}$ & 0.005 & $2.445 \dagger$ & $0.025 \mathrm{NS}$ & $1 \cdot 284 \ddagger$ & $0.03 \mathrm{NS}$ & 38 \\
\hline 2nd Quartile & $1 \cdot 195^{\star}$ & 0.005 & $2.378 \dagger$ & $0.025 \mathrm{NS}$ & $1.294 \ddagger$ & $0.03 \mathrm{NS}$ & 36 \\
\hline 3rd Quartile & $1 \cdot 197^{\star}$ & 0.004 & $2.363 \dagger$ & 0.024 NS & $1.309 \ddagger$ & $0.03 \mathrm{NS}$ & 39 \\
\hline 4th Quartile & $1 \cdot 212^{*}$ & 0.005 & $2.427 \dagger$ & $0.026 \mathrm{NS}$ & $1.278 \ddagger$ & $0.03 \mathrm{NS}$ & 34 \\
\hline Mean & 1.202 & 0.005 & 2.403 & 0.025 & 1.293 & 0.03 & 147 \\
\hline Reference range§ & \multicolumn{2}{|c|}{$1.18-1.30$} & \multicolumn{2}{|c|}{$2.15-2.51$} & \multicolumn{2}{|c|}{$0.85-1.50$} & \\
\hline
\end{tabular}

ANCOVA, analysis of covariance; S-PTH, serum parathyroid hormone; S-25(OH)D, serum 25-hydroxy vitamin D; S-Pi, serum phosphate. ${ }^{*} P<0.05$ with ANCOVA adjusted for S-PTH, S-25(OH)D and S-Pi concentrations, and use of contraceptives.

† NS $(P>0.05)$ with ANCOVA adjusted for S-PTH, S-25 $(\mathrm{OH}) \mathrm{D}$ and S-Pi concentrations, and use of contraceptives.

$\ddagger N S(P>0.05)$ with ANCOVA adjusted for S-PTH, S-iCa and S-25(OH)D concentrations, and use of contraceptives.

$\S$ Medix Laboratoriot (http://www.medix.fi).

5th percentile intake was 0.38 (weight ratio 0.49 ) and at the 95 th percentile intake was 0.74 (weight ratio 0.96 ).

Effect of dietary calcium:phosphorus ratios on serum parathyroid hormone. The mean S-PTH concentration differed significantly between the Ca:P quartiles $(P=0 \cdot 014$, ANOVA), being higher in the 1 st quartile than in the others. To exclude the possibility that these differences are not due to differences in relevant covariates, we adjusted the S-PTH means for the following variables $(\mathrm{S}-\mathrm{iCa}$ and $\mathrm{S}-25(\mathrm{OH}) \mathrm{D}$ concentrations and use of contraceptives). After these adjustments, the S-PTH differences remained practically the same, as did their statistical significance $(P=0.021$, ANCOVA).
The mean S-PTH values and the statistical differences of the 2nd, 3rd and 4th quartiles from the 1st quartile are shown in Fig. 3. The mean S-PTH concentration was $30 \%$ higher in the 1st quartile than in the combined group of the $2 \mathrm{nd}, 3 \mathrm{rd}$ and 4th quartiles $(P=0.002)$. No differences in the mean S-PTH concentrations were present among the 2 nd, 3 rd and 4th quartiles, and the smallest $P$-value among quartiles in the ANCOVA model was only $0 \cdot 88$.

Effect of dietary calcium:phosphorus ratios on urinary excretion of calcium and phosphate. The dietary Ca:P ratio significantly affected the 24-h U-Ca excretion $(P=0 \cdot 047$, ANOVA). The mean U-Ca excretion in the 1st quartile was
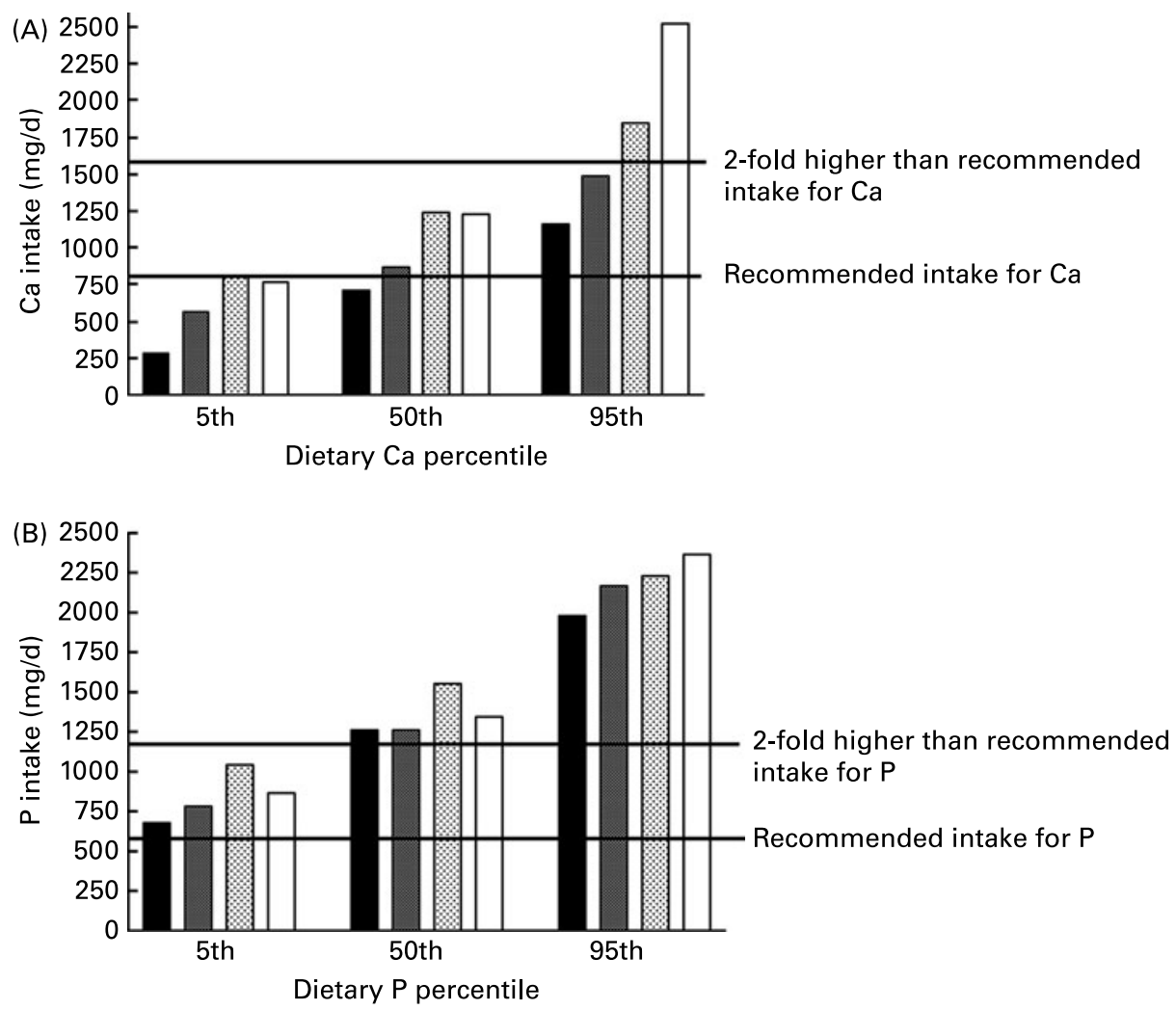

Fig. 1. The 5th, 50th and 95th percentiles of dietary calcium (mg/d; panel A) and phosphorus (mg/d; panel B) intakes in each calcium:phosphorus quartile. Calcium:phosphorus molar ratios were $\leq 0.50,0.51-0.57,0.58-0.64$ and $\geq 0.65$ in the 1st, 2nd, 3rd and 4th quartiles, respectively. $\mathbf{0}$, 1st quartile; 图, 2nd quartile; 图, 3rd quartile; $\square$, 4th quartile. 


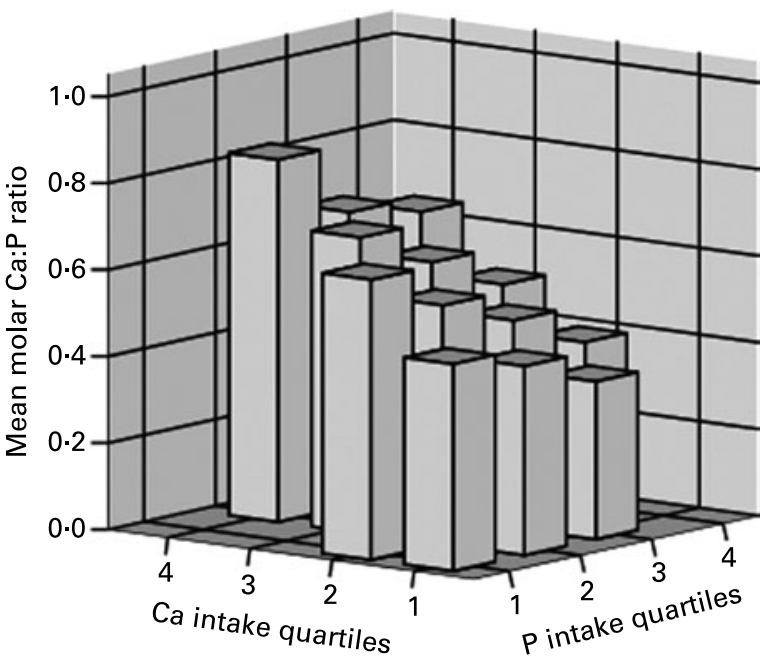

Fig. 2. The mean molar dietary calcium:phosphorus ratios ( $y$-axis) in each calcium ( $x$-axis) and phosphorus ( $z$-axis) intake quartile. Dietary calcium intake in calcium quartiles was $<770,771-997,998-1251$ and $>1251 \mathrm{mg} / \mathrm{d}$ in the 1st, $2 \mathrm{nd}$, 3rd and 4th quartiles, respectively. Dietary phosphorus intake in phosphorus quartiles was <1122, 1122-1347, 1348-1643 and $>1643 \mathrm{mg} / \mathrm{d}$ in the $1 \mathrm{st}, 2 \mathrm{nd}$, 3rd and 4 th quartiles, respectively.

higher than in the other quartiles. After adjusting the U-Ca means for the following relevant covariates (dietary $\mathrm{Na}$ and protein intakes, S-PTH and $\mathrm{S}-25(\mathrm{OH}) \mathrm{D}$ concentrations, and use of contraceptives), similar effects remained in the U-Ca differences and in their statistical significance $(P=0.051$, ANCOVA). The mean U-Ca values are shown in Fig. 4. When comparing the 2 nd, 3rd and 4 th quartiles as a combined group with the 1st quartile, the mean U-Ca excretion was about $30 \%$ higher in the latter $(P=0.006$, ANCOVA). In addition, the mean $\mathrm{U}-\mathrm{Ca}$ excretion did not vary between the $2 \mathrm{nd}$, 3rd and 4th quartiles (ANCOVA; $P=0.58-0.90$ ).

The mean 24-h U-Pi excretion did not differ between the Ca:P quartiles ( $P=0 \cdot 33$, ANOVA). However, after adjustment for relevant covariates (dietary $\mathrm{Na}$ intake, S-PTH and $\mathrm{S}-25(\mathrm{OH}) \mathrm{D}$ concentrations, and use of contraceptives), the mean U-Pi excretion tended to be different between the quartiles $(P=0 \cdot 13$, ANCOVA). In the 1 st quartile, U-Pi excretion was $6-17 \%$ higher than in the 2 nd, 3rd and 4th quartiles. Furthermore, when comparing the 2nd, 3rd and 4th quartiles as one group with the 1st quartile, the mean $\mathrm{U}-\mathrm{Pi}$ excretion was about $13 \%$ higher in the 1 st quartile $(P=0 \cdot 055$, ANCOVA).

Effect of dietary calcium:phosphorus ratios on serumionised calcium, calcium and phosphate. The mean S-iCa concentration differed significantly between the quartiles $(P=0.027$, ANOVA), being the highest in the 4th quartile. $\mathrm{S}$-iCa concentration in the 4 th quartile differed significantly from all other quartiles $(P=0.050, P=0.006$ and $P=0.013$ in the 2nd, 3rd and 4th quartiles, respectively, Fisher's LSD comparisons, ANOVA). After adjusting the S-iCa means for the relevant variables (S-PTH, S-25 $(\mathrm{OH}) \mathrm{D}$ and S-Pi concentrations, and use of contraceptives), the $\mathrm{S}-\mathrm{iCa}$ differences remained practically the same, as did their statistical significance $(P=0 \cdot 040$, ANCOVA; Table 2$)$. However, the 1st quartile did not differ significantly from the 4th quartile $(P=0 \cdot 242$, Fisher's LSD comparisons, ANCOVA), although the 2nd $(P=0 \cdot 010$, Fisher's LSD comparisons, ANCOVA)

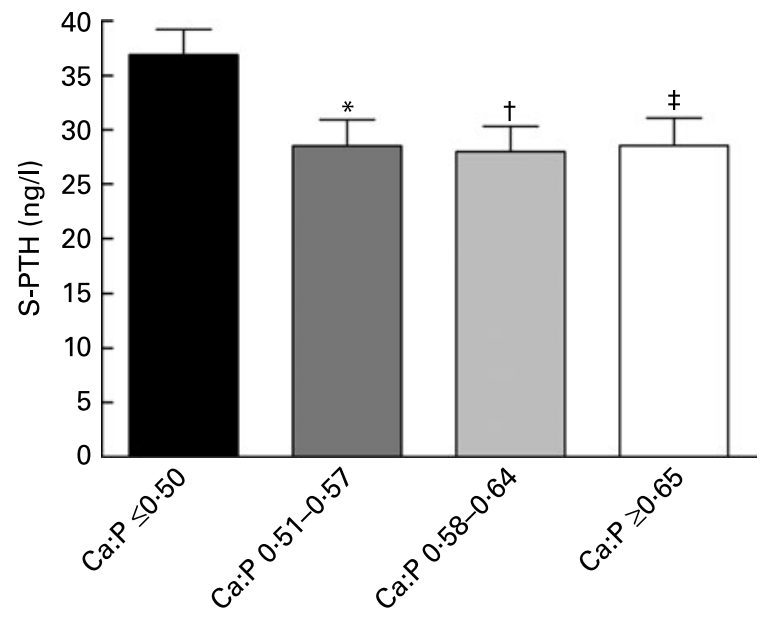

Fig. 3. Effects of calcium:phosphorus ratios on serum parathyroid hormone (S-PTH) concentration (means with their standard errors) in the different quartiles. The covariates included serum 25-hydroxyvitamin D and ionised calcium concentrations, and use of contraceptives. Analysis of covariance (ANCOVA) was performed. Mean value was significantly different from that of the 1st quartile: ${ }^{\star} P=0.014, \dagger P=0.07, \ddagger P=0.017$ (Fisher's least significant difference comparison, ANCOVA). $\square$, 1st quartile; $\square$, 2nd quartile; $\square$, 3rd quartile; $\square$, 4th quartile.

and 3rd $(P=0 \cdot 022$, Fisher's LSD comparisons, ANCOVA) quartiles did (Table 2).

While no differences existed in $\mathrm{S}$-Ca concentration between the Ca:P quartiles by ANOVA $(P=0 \cdot 27), S-C a$ concentration tended to differ between quartiles $(P=0 \cdot 061$, ANCOVA) after adjustment for relevant covariates (S-PTH, S-25(OH)D and S-Pi concentrations, and use of contraceptives; Table 2).

The mean S-Pi concentration did not differ between the quartiles ( $P=0 \cdot 85$, ANOVA). After adjusting the S-Pi means for relevant covariates (S-PTH, S-25(OH)D and S-iCa concentrations, and use of contraceptives), no differences between the quartiles were found ( $P=0 \cdot 87$, ANCOVA; Table 2$)$.

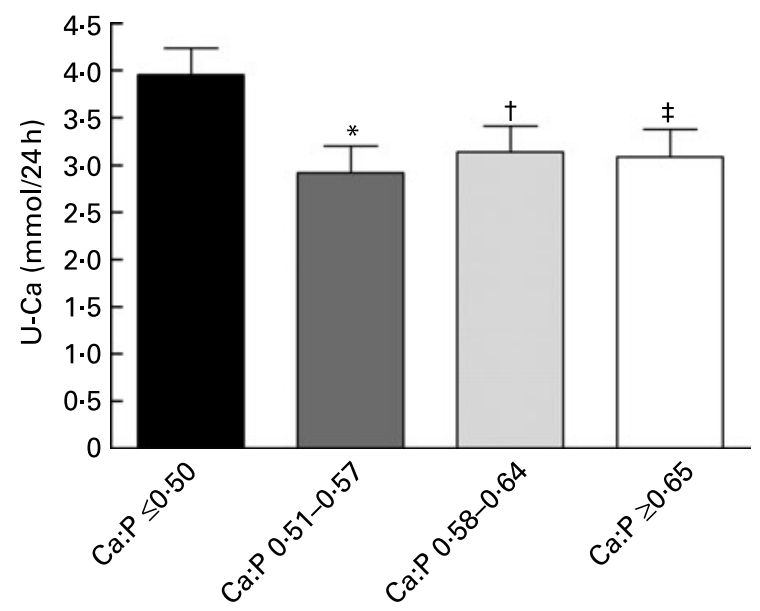

Fig. 4. Effects of calcium:phosphorus ratios on 24-h urinary calcium (U-Ca) excretion (means with their standard errors) in the different quartiles. The covariates included serum 25-hydroxyvitamin D and parathyroid hormone concentrations, dietary sodium and protein intakes, and use of contraceptives. Analysis of covariance (ANCOVA) was performed. Mean value was significantly different from that of the 1 st quartile: ${ }^{*} P=0.010, \dagger P=0.040$, $\ddagger P=0.035$ (Fisher's least significant difference comparison, ANCOVA). $\mathbf{\square}$, 1st quartile; $\square$, 2nd quartile; $\square$, 3rd quartile; $\square$, 4th quartile. 


\section{Discussion}

In this cross-sectional study, low habitual dietary $\mathrm{Ca}: \mathrm{P}$ ratios interfered with $\mathrm{Ca}$ metabolism in healthy women with an adequate dietary $\mathrm{Ca}$ intake. Interestingly, the lowest quartile $(\mathrm{Ca}: \mathrm{P}$ molar ratio $\leq 0 \cdot 50)$ differed from all other quartiles by increasing both S-PTH concentration and U-Ca excretion. In fact, quartiles other than 1 st one had similar effects on the markers measured, except on $\mathrm{S}-\mathrm{iCa}$ concentration. The present findings imply that a cut-off $\mathrm{Ca}: \mathrm{P}$ ratio may exist, lower than suggested $\mathrm{Ca}: \mathrm{P}$ molar ratio of $1^{(4-7)}$, below which the effects on mineral metabolism and bone health are more severe. It is noteworthy that dietary $\mathrm{Ca}$ intake among our participants was mostly adequate or high (mean $\mathrm{Ca}$ intake $1056 \mathrm{mg} / \mathrm{d}$ ). Even in the 1 st quartile, the mean $\mathrm{Ca}$ intake was nearly $750 \mathrm{mg} / \mathrm{d}$. This intake reflects the high dairy product consumption of participants. More details of participants' consumption of dairy products have been provided elsewhere ${ }^{(44)}$. Nevertheless, none of the participants achieved the suggested $\mathrm{Ca}: \mathrm{P}$ molar ratio of 1 in their diets. This is mainly due to the excessive $\mathrm{P}$ content in their habitual diets, rather than low dietary $\mathrm{Ca}$ intake, as mean dietary $\mathrm{P}$ intake exceeded 2.4-fold, and mean dietary $\mathrm{Ca}$ intake 1.3-fold the Nordic nutritional recommendations for $\mathrm{P}(600 \mathrm{mg} / \mathrm{d})$ and $\mathrm{Ca}$ $(800 \mathrm{mg} / \mathrm{d})^{(43)}$. These intakes corresponded to the average intake of $\mathrm{Ca}$ and $\mathrm{P}$ in Finnish females in $2007^{(8)}$.

Speculation has arisen as to whether the dietary $\mathrm{Ca}: \mathrm{P}$ ratio is clinically significant in adult human subjects ${ }^{(21)}$. In infants and children, a dietary $\mathrm{Ca}: \mathrm{P}$ weight ratio of 1.5 is considered to be ideal for optimal growth ${ }^{(9)}$. However, in adult diets, the $\mathrm{Ca}: \mathrm{P}$ ratio varies, being highest in dairy products ${ }^{(45)} \mathrm{P}$ is present in a wide range of foods, while about $75 \%$ of Ca comes from dairy products ${ }^{(8)}$. In addition, $\mathrm{P}$ is added to foods as a phosphate-containing food additive, further increasing already high $\mathrm{P}$ intake. Although, some foods rich in $\mathrm{P}$ are also good sources of $\mathrm{Ca}$, e.g. dairy products, many others contain very little $\mathrm{Ca}$. Among the participants in the present study, the intake of $\mathrm{P}$ from milk and cheese was higher in the 3rd and 4th $\mathrm{Ca}: \mathrm{P}$ quartiles indicating that dairy products represent a higher proportion of the total $\mathrm{P}$ intake in these quartiles. Therefore, if the habitual diet lacks dairy products, the dietary $\mathrm{Ca}: \mathrm{P}$ ratio will easily drop below optimal levels. Very low $\mathrm{Ca}: \mathrm{P}$ ratios $(\leq 0.25)$ have been reported in diets of young girls and boys in Poland ${ }^{(18)}$, as well as in teenagers and young adults in $\mathrm{USA}^{(11)}$.

Calvo et al. ${ }^{(46)}$ found that a high-P $(1700 \mathrm{mg} / \mathrm{d})$, low-Ca diet $(400 \mathrm{mg} / \mathrm{d})$ consumed by young adults for $8 \mathrm{~d}$ resulted in elevated S-PTH. Interestingly, S-PTH concentrations increased more in females than in males. In an additional 4-week study in young females only, S-PTH levels increased in response to a high-P, low-Ca diet, but no changes occurred in another central regulator of $\mathrm{Ca}$ and bone metabolism, serum $1,25-(\mathrm{OH})_{2} \mathrm{D}$ concentration, which usually increases in response to low $\mathrm{Ca}$ intake $^{(25)}$. The authors suggested that the usual homoeostatic mechanism used when dietary $\mathrm{Ca}$ is limited is disturbed by chronic high $\mathrm{P}$ intake. Similar results were observed in a 24-h controlled study in healthy young females, whose S-PTH concentrations increased in a dose-dependent manner in response to increasing $\mathrm{P}$ intake and decreasing $\mathrm{Ca}: \mathrm{P}$ ratio, although no changes in serum $1,25-(\mathrm{OH})_{2} \mathrm{D}$ concentrations occurred ${ }^{(26)}$. Unfortunately, serum $1,25-(\mathrm{OH})_{2} \mathrm{D}$ concentrations were not measured in the present study, but in line with observations in earlier interventions ${ }^{(25,46)}$ and short-term controlled studies $^{(26,27)}$, higher S-PTH concentrations were found in participants with low dietary $\mathrm{Ca}: \mathrm{P}$ ratios $(\mathrm{Ca}: \mathrm{P}$ molar ratio $\leq 0 \cdot 50$ ). While the mean intake of $\mathrm{P}$ in all quartiles was over twofold higher $(>1200 \mathrm{mg} / \mathrm{d})$ than dietary guidelines ${ }^{(4,43)}$, the mean intake of $\mathrm{Ca}$ was slightly below recommended levels ${ }^{(4,43)}$ in the 1 st quartile only $(742 \mathrm{mg} / \mathrm{d})$. In fact, excluding the 1st quartile revealed similar effects on S-PTH in the other quartiles. This similarity may be explained by higher intake of $\mathrm{Ca}$, as $\mathrm{Ca}$ intake has been observed to decrease absorption of $\mathrm{P}$ in the intestine ${ }^{(47)}$ and to suppress S-PTH concentration induced by high $\mathrm{P}$ intake ${ }^{(27)}$. S-PTH concentration is apparently lower in the mornings ${ }^{(28)}$. In line with this, we have previously demonstrated that P-containing meals increase S-PTH above the higher reference limit on study days, with S-PTH values remaining elevated the following mornings ${ }^{(26)}$, indicating the presence of a transient secondary hyperparathyroidism. In the present study, higher S-PTH concentrations could have been noted if samples other than morning fasting samples had also been collected. Nevertheless, the finding of increased mean S-PTH only in the 1st quartile supported the importance of higher dietary $\mathrm{Ca}: \mathrm{P}$ ratios and the vital role of adequate $\mathrm{Ca}$ intake simultaneously with high dietary $\mathrm{P}$ intake in habitual diets.

An unexpected physiological increase in 24-h U-Ca excretion was observed in the $1 \mathrm{st}$ quartile. This was unexpected, since the mean dietary $\mathrm{Ca}$ intake and $\mathrm{Ca}: \mathrm{P}$ ratio in the 1st quartile were the lowest. Furthermore, the mean $\mathrm{S}$-PTH concentration in this quartile was the highest. The present finding is interesting, as in normal physiological conditions elevated S-PTH leads to decreased U-Ca excretion. In primary hyperparathyroidism, an increase in U-Ca excretion is, however, often seen ${ }^{(48)}$. The U-Ca finding suggests that low dietary $\mathrm{Ca}: \mathrm{P}$ ratios in habitual diets somehow interfere with the homoeostasis of $\mathrm{Ca}$ metabolism. An increase in S-PTH due to a low $\mathrm{Ca}: \mathrm{P}$ ratio would be expected to increase bone resorption, and some of the extra $\mathrm{Ca}$, which has been released from bone, to be excreted in urine. Elevated U-Ca excretion might therefore reflect an increase in bone resorption.

$\mathrm{U}-\mathrm{Ca}$ excretion is an important determinant of Ca retention in the healthy human body. In a controlled situation, U-Ca excretion has been strongly correlated with acute $\mathrm{Ca}$ intake $^{(37)}$. In a controlled short-term study, when dietary $\mathrm{P}$ intake was high $(1850 \mathrm{mg} / \mathrm{d})$, U-Ca excretion increased with increasing dietary $\mathrm{Ca}$ intake and $\mathrm{Ca}: \mathrm{P}$ ratio in a dose-dependent manner in healthy women ${ }^{(27)}$. In addition, 24-h U-Ca excretion was similar with $P$ intakes of 1245 and $1995 \mathrm{mg} / \mathrm{d}$ when $\mathrm{Ca}$ intake was very low $(250 \mathrm{mg} / \mathrm{d})$. These findings indicate that U-Ca excretion might not diminish after a certain high $\mathrm{P}$ intake, which may result in an unfavourable $\mathrm{Ca}$ balance $^{(26)}$. Moreover, low $\mathrm{Ca}$ intake and high U-Ca excretion have been assumed to reduce $\mathrm{Ca}$ accretion in bone of young adults during growth and to have a negative impact on skeletal development ${ }^{(49)}$. In the present study, U-Ca excretion was expected to be the highest in the 3rd and 4th quartiles, as dietary $\mathrm{P}$ intake was high in all of the quartiles, but dietary $\mathrm{Ca}$ intake was significantly higher only in the 3rd and 4th quartiles. Furthermore, in the 1st quartile, the mean $\mathrm{Ca}$ intake was slightly below recommended levels $(\geq 800 \mathrm{mg} / \mathrm{d})^{(4,43)}$. 
In fact, after excluding the 1st quartile, the other quartiles were highly similar in their effects on U-Ca excretion. This implies that in habitual diets with excessive dietary $\mathrm{P}$ intake an adequate dietary $\mathrm{Ca}$ intake is needed to overcome the interfering effects of low $\mathrm{Ca}: \mathrm{P}$ ratios on $\mathrm{Ca}$ excretion.

In summary, low dietary $\mathrm{Ca}: \mathrm{P}$ ratios in habitual diets of healthy women affected both S-PTH and Ca metabolism. Interestingly, the lowest $\mathrm{Ca}: \mathrm{P}$ quartile differed from all other quartiles in a negative manner. The results suggested that such low $\mathrm{Ca}: \mathrm{P}$ ratios $(\mathrm{Ca}: \mathrm{P}$ molar ratio $\leq 0.50)$ in diets may disturb $\mathrm{Ca}$ metabolism and negatively affect bone in healthy subjects, as indicated by higher S-PTH and $\mathrm{U}-\mathrm{Ca}$ levels together. However, whether it is necessary to reach a Ca:P molar ratio of 1 in diets is unknown. Even participants with a high dietary $\mathrm{Ca}$ intake did not achieve the suggested $\mathrm{Ca}: \mathrm{P}$ ratio of 1 . The present results imply that a $\mathrm{Ca}: \mathrm{P}$ molar ratio higher than 0.50 is sufficient when dietary $\mathrm{Ca}$ intake is at the recommended level. However, higher $\mathrm{Ca}: \mathrm{P}$ ratios might be needed if dietary $\mathrm{Ca}$ intake drops markedly below the nutritional recommendations. The present study also indicated that consumption of a large excess of dietary $\mathrm{P}$ is not optimal for mineral metabolism and bone health. In Western diets, low $\mathrm{Ca}: \mathrm{P}$ ratios are common. Thus, more attention should be focused on decreasing excessively high $\mathrm{P}$ intake and increasing $\mathrm{Ca}$ intake to meet dietary guidelines. In Western diets, dairy products consumption will easily ensure adequate $\mathrm{Ca}$ intake. High dietary $\mathrm{P}$ intake, in turn, will be reduced by restricting the consumption of highly processed foods and increasing the consumption of raw and unprocessed foods. Nevertheless, increasing dietary $\mathrm{Ca}$ intake far beyond the nutritional recommendations should be avoided, as it might lead to other health risks. Identifying persons at risk of having low $\mathrm{Ca}: \mathrm{P}$ ratios in their habitual diets would be useful. Also, because dietary Ca intake was generally adequate among our participants, additional studies are needed to investigate the impact of dietary $\mathrm{Ca}: \mathrm{P}$ ratios in populations where low dietary $\mathrm{Ca}$ intake is common.

\section{Acknowledgements}

The Academy of Finland, the Ministry of Education, the Finnish Graduate School on Applied Bioscience and the Juho Vainio Foundation financially supported the present study. M. U. M. K., M. M. L. L. and T. A. O. conducted the experimental work and laboratory analyses. V. E. K., M. U. M. K., H. J. R. and C. J. E. L.-A. designed the study. V. E. K. conducted the data analysis, carried out the statistical analysis and prepared the manuscript for publication. C. J. E. L.-A., M. M. L. L., M. U. M. K., H. J. R. and T. A. O. assisted with the manuscript revision. C. J. E. L.-A. was the principal investigator of the study. None of the contributing authors had any financial or personal interests in any of the organisations sponsoring the present research. We thank all volunteers for their participation.

\section{References}

1. Tang BPM, Eslick GD, Nowson C, et al. (2007) Use of calcium or calcium in combination with vitamin $\mathrm{D}$ supplementation to prevent fractures and bone loss in people aged 50 years and older: a meta-analysis. Lancet 370, 657-666.
2. Bischoff-Ferrari HA, Willett WC, Wong JB, et al. (2005) Fracture prevention with vitamin D supplementation: a metaanalysis of randomized controlled trials. JAMA 293, 2257-2264.

3. Welten DC, Kemper HCG, Post GB, et al. (1995) A meta-analysis of the effects of calcium intake on bone mass in young and middle aged females and males. J Nutr 125, 2802-2813.

4. Advisory Committee of Government (2005) Finnish Nutrition Recommendations - Diet and Physical Activity in Balance. Helsinki: Edita.

5. Whybro A, Jagger H, Barker M, et al. (1998) Phosphate supplementation in young men: lack of effect on calcium homeostasis and bone turnover. Eur J Clin Nutr 52, 29-33.

6. Calvo MS \& Park YK (1996) Changing phosphorus content of the U.S. diet: potential for adverse effects on bone. J Nutr 126, $1168 \mathrm{~S}-1180 \mathrm{~S}$.

7. SCF (Scientific Committee on Food) (1993) Reports of the Scientific Committee on Food (31st Series). Nutrient and Energy Intakes for the European Communities, pp. 177-189. Luxembourg: Commission of the European Community. http:// europa.eu.int/comm/food/fs/sc/scf/out89.pdf.

8. Paturi M, Tapanainen H, Reinivuo H, et al. (editors) (2008) The National FINDIET 2007 Survey. Kansanterveyslaitoksen julkaisuja B23/2008. Helsinki, Finland: Yliopistopaino.

9. European Food Safety Authority (EFSA) (2005) Opinion of the scientific panel on dietetic products, nutrition and allergies on a request from the commission related to the tolerable upper intake level of phosphorus. http://www.efsa.europa.eu/EFSA/ efsa_locale-1178620753812_1178620767179.htm (accessed October 2008)

10. Gronowska-Senger A \& Kotanska P (2004) Phosphorus intake in Poland in 1994-2000. Rocz Państw Zakt Hig 55, 39-49 (abstract).

11. Calvo MS (1993) Dietary phosphorus, calcium metabolism and bone. J Nutr 123, 1627-1633.

12. Henrix P, Van Cauwenbergh R, Robberrecht HJ, et al. (1995) Measurement of the daily dietary calcium and magnesium intake in Belgium, using duplicate portion sampling. Z Lebensm Unters Forsch 201, 213-217 (abstract).

13. Bryant RJ, Cadogan J \& Weaver CM (1999) The new dietary reference intakes for calcium: implications for osteoporosis. $J$ Am Coll Nutr 18, 406S-412S.

14. Guéguen L \& Pointillart A (2000) The bioavailability of dietary calcium. J Am Coll Nutr 19, 119S-136S.

15. Lombardi-Boccia G, Aguzzi A, Cappelloni M, et al. (2003) Total-diet study: dietary intakes of macro elements and trace elements in Italy. Br J Nutr 90, 1117-1121.

16. Salamoun MM, Kizirian AS, Tannous RI, et al. (2005) Low calcium and vitamin D intake in healthy children and adolescents and their correlates. Eur J Clin Nutr 59, 177-184.

17. Brot C, Jorgensen N, Madsen OR, et al. (1999) Relationships between bone mineral density, serum vitamin $\mathrm{D}$ metabolites and calcium:phosphorus intake in healthy perimenopausal women. J Intern Med 245, 509-516.

18. Chwojnowska Z, Charzewska J, Chabros E, et al. (2002) Contents of calcium and phosphorus in the diet of youth from Warsaw elementary schools. Rocz Panstw Zakl Hig 53, 157-165.

19. Takeda E, Sakamoto K, Yokota K, et al. (2002) Phosphorus supply per capita from food in Japan between 1960 and 1995. J Nutr Sci Vitaminol 48, 102-108 (abstract).

20. Koshihara M, Katsumata S-I, Uehara M, et al. (2005) Effects of dietary phosphorus intake on bone mineralization and calcium absorption in adult female rats. Biosci Biotechnol Biochem 69 , $1025-1028$.

21. Sax L (2001) The Institute of Medicine's 'Dietary reference intake' for phosphorus: a critical perspective. J Am Coll Nutr 20, 271-278. 
22. Standing Committee on the Scientific Evaluation of Dietary Reference Intakes, Food and Nutrition Board, Institute of Medicine \& National Research Council (1997) Dietary Reference Intakes: Calcium, Phosphorus, Magnesium, Vitamin D, and Fluoride. Washington, DC: National Academy Press.

23. Metz JA, Anderson JJ \& Gallagher PN Jr (1993) Intakes of calcium, phosphorus, and protein, and physical-activity level are related to radial bone mass in young adult women. Am J Clin Nutr 58, 537-542.

24. Teegarden D, Lyle RM, McCabe GP, et al. (1998) Dietary calcium, protein, and phosphorus are related to bone mineral density and content in young women. Am J Clin Nutr 68, 749-754.

25. Calvo MS, Kumar R \& Heath H 3rd (1990) Persistently elevated parathyroid hormone secretion and action in young women after four weeks of ingesting high phosphorus, low calcium diets. $J$ Clin Endocrinol Metab 70, 1334-1340.

26. Kemi VE, Kärkkäinen MUM \& Lamberg-Allardt CJE (2006) High phosphorus intakes acutely and negatively affect calcium and bone metabolism in a dose-dependent manner in healthy young females. Br J Nutr 96, 545-552.

27. Kemi VE, Kärkkäinen MUM, Karp HJ, et al. (2008) Increased calcium intake does not completely counteract the effects of increased phosphorus intake on bone: an acute dose-response study in healthy female. $B r J$ Nutr 99, 832-839.

28. Herfarth K, Schmidt-Gayk H, Graf S, et al. (1992) Circadian rhythm and pulsatility of parathyroid hormone secretion in man. Clin Endocrinol 37, 511-519.

29. Slatopolsky E, Finch J, Denda M, et al. (1996) Phosphorus restriction prevents parathyroid gland growth. High phosphorus directly stimulates PTH secretion in vitro. J Clin Invest 97 , 2534-2540.

30. Miyamoto K, Tatsumi S, Segawa H, et al. (1999) Regulation of PiT-1, a sodium-dependent phosphate co-transporter in rat parathyroid glands. Nephrol Dial Transplant 14, Suppl. 1, S73-S75.

31. Kärkkäinen MUM, Lamberg-Allardt CJE, Ahonen $\mathrm{S}$, et al. (2001) Does it make a difference how and when you take your calcium? The acute effects of calcium on calcium and bone metabolism. Am J Clin Nutr 74, 335-342.

32. Sadideen H \& Swaminathan R (2004) Effect of acute oral calcium load on serum PTH and bone resorption in young healthy subjects: an overnight study. Eur J Clin Nutr 58, $1661-1665$.

33. Liu CC \& Kalu DN (1990) Human parathyroid hormone-(1-34) prevents bone loss and augments bone formation in sexually mature ovariectomized rats. J Bone Miner Res 5, 973-982.

34. Hodsman AB, Steer BM, Fraher LJ, et al. (1991) Bone densitometric and histomorphometric responses to sequential human parathyroid hormone (1-38) and salmon calcitonin in osteoporotic patients. Bone Miner 14, 67-83.

35. Tam CS, Heersche JNM, Murray TM, et al. (1982) Parathyroid hormone stimulates the bone apposition rate independently of its resorptive action: differential effects of intermittent and continuous administration. Endocrinology 110, 506-512.

36. Schiller PC, Dippolito G, Roos BA, et al. (1999) Anabolic or catabolic responses of MC3T3-E1 osteoblastic cells to parathyroid hormone depend on time and duration of treatment. J Bone Miner Res 14, 1504-1512.

37. Charles P (1992) Calcium absorption and calcium bioavailability. J Intern Med 231, 161-168.

38. Bell RR, Draper HH, Tzeng DYM, et al. (1977) Physiological responses of human adults to foods containing phosphate additives. $J$ Nutr 107, 42-50.

39. Murer H, Forster I, Hernando N, et al. (1999) Posttranscriptional regulation of the proximal tubule $\mathrm{NaPi}-\mathrm{II}$ transporter in response to PTH and dietary Pi. Am J Physiol 46, F676-F684.

40. Lamberg-Allardt CJ, Outila TA, Kärkkäinen MU, et al. (2001) Vitamin D deficiency and bone health in healthy adults in Finland: could this be a concern in other parts of Europe? J Bone Miner Res 16, 2066-2073.

41. Kärkkäinen M, Outila T \& Lamberg-Allardt C (1998) Habitual dietary calcium intake affects serum parathyroid hormone concentration in postmenopausal women with a normal vitamin D status. Scand J Nutr 42, 104-107.

42. Teegarden D, Legowski P, Gunther CW, et al. (2005) Dietary calcium intake protects women consuming oral contraceptives from spine and hip bone loss. J Clin Endocrinol Metab 90, $5127-5133$.

43. Nordic Council of Ministers (2004) Nordic Nutrition Recommendations 2004. Integrating Nutrition and Physical Activity. Århus: Scanprint A/S.

44. Kemi VE, Rita HJ, Kärkkäinen MU, et al. (2009) Habitual high phosphorus intakes and foods with phosphate additives negatively affect serum parathyroid hormone concentration: a cross-sectional study on healthy premenopausal women. Public Health Nutr 12, 1885-1892.

45. National Public Health Institute, Nutrition Unit (2008) Fineli (®)- Finnish Food Composition Database. Release 6. Helsinki, Finland. http://www.fineli.fi/ (accessed September 2008).

46. Calvo MS, Kumar R \& Heath H 3rd (1988) Elevated secretion and action of serum parathyroid hormone in young adults consuming high phosphorus, low calcium diets assembled from common foods. J Clin Endocrinol Metab 66, 823-829.

47. Nolan CR \& Cunibi WY (2003) Calcium salts in the treatment of hyperphosphatemia in hemodialysis patients. Curr Opin Nephrol Hypertens 12, 373-379.

48. American Society for Bone and Mineral Research (2008) Primer on the Metabolic Bone Diseases and Disorders of Mineral Metabolism. Washington, DC: The Sheridan Press.

49. Matkovic V, Ilich JZ \& Andon MB (1995) Urinary calcium, sodium, and bone mass of young females. Am J Clin Nutr 62, 417-425. 